\title{
SAC-OCDMA system performance using narrowband Bragg filter encoders and decoders
}

\author{
S. Boukricha' ${ }^{1} \cdot$ K. Ghoumid ${ }^{1} \cdot$ S. Mekaoui ${ }^{2} \cdot$ E. Ar-Reyouchi $^{3} \cdot$ H. Bourouina $^{4} \cdot$ R. $_{\text {Yhiaoui }}{ }^{5}$
}

Received: 14 January 2020 / Accepted: 5 April 2020 / Published online: 2 May 2020

(c) Springer Nature Switzerland AG 2020

\begin{abstract}
In this paper, we have studied a Spectral Amplitude Coding Optical Code Division Multiple Access (SAC-OCDMA) system performance using fiber Bragg gratings equivalent to very narrow filters used in the system as encoders and decoders in both the transmitter and the receiver block. The system performance depends on several variables such as: the optical power; the fiber length; the data rate and the bandwidth. Different simulations have been realized in terms of the bit error rate (BER) and the quality factor (Q) to evaluate the effect of each parameter on the system performance and also to examine the impact of number of users. The obtained results using Optisystem network show clearly that the studied SAC-OCDMA system of three users remains efficient for fiber lengths up to $25 \mathrm{~km}$ at a data rate of $200 \mathrm{Mbits} / \mathrm{s}$ and a FBGs bandwidth of $0.6 \mathrm{~nm}$. These results are realized with an acceptable bit error rate $B E R<10^{-9}$. In addition, a SAC-OCDMA system of 9 users was also simulated to assess the effect of the number of users. The results obtained show that for a fiber length $L=5 \mathrm{Km}$, the system remains efficient for a number of users set at 8 users, then the longer the fiber length increases the more the number of possible users decreases. For $L=35 \mathrm{Km}$, the number of users for whom all users obtain a good BER value is 6 users.
\end{abstract}

Keywords Optical Code Division Multiple Access (OCDMA) - Spectral Amplitude Coding Optical Code Division Multiple Access (SAC-OCDMA) · Narrow-band filter · Fiber Bragg gratings (FBGs)

\section{Introduction}

Over the last two decades, the demand for telecommunications services with very high bandwidths, high data rates and good service quality has continued to grow continuously. These constant demands are due to the increasingly diverse requirements and the need for faster and safer communication systems. Several solutions have been implemented in different categories of access networks to meet the growing need for data sharing between users [1-5].
The transmission throughput and bandwidth sharing are strongly related to the physical limitations of transmission systems and the techniques implemented for sharing resources between users. Consequently, different multiple access techniques allowing several users to share the same channel bandwidth have been introduced $[6,7]$.

Optical Code Division Multiple Access (OCDMA) is an interesting multiple access technology in the telecommunications field $[8,9]$. This multiplexing technique is based on the concept of spectrum spreading which allows power spreading over a wide frequency band and confers to the transmitted signal a noise like form which is hard to be

S. Boukricha, s.boukricha@ump.ac.ma; K. Ghoumid, k.ghoumid@ump.ac.ma |'Department of Electronics, Informatics and Telecommunications, ENSAO, Mohammed Premier University, Oujda, Morocco. ${ }^{2}$ Faculty of Electronics and Computer Science, University of Science and Technology Houari Boumediene (USTHB), Bab Ezzouar, Algeria. ${ }^{3}$ Department of Telecommunication and Computer Science, Abdelmalek Essaadi University, Tétouan, Morocco. ${ }^{4}$ Physics Laboratory, Normal School of Bou-Saada, 28200 M'Sila, Algeria. ${ }^{5}$ Department of Electronics, FEMTO-ST Institut, Franche-Comté University, Besançon, France. 
detected by not concerned receivers [10]. Thus, making the transmission less sensitive to selective frequency fluctuations while ensuring very good security [11].

Another advantage of this technique is that it simultaneously exploits all the bandwidth, which allows a better management of the available resources. In addition, the orthogonality of the code sequences reduces users' interferences affecting the performance of an OCDMA system [12].

OCDMA provides the realization of all-optical systems based on optical coding and decoding devices allowing an asynchronous transmission of the transported signals. It is based on the principle of identifying each user by a unique optical code. Each code characterizes a user during the passage through the optical transmission channel [13].

In OCDMA systems, the coding process can be done in different ways with different categories, including: OCDMA by time encoding (DS-OCDMA), OCDMA by phase spectral encoding (SPE-OCDMA) and OCDMA by spectral-temporal encoding ( $\lambda-t$ OCDMA) [14-16].In this paper, we study a particular type of OCDMA namely the Spectra Amplitude Coding (SAC-OCDMA) $[17,18]$ which is considered as the most attractive due to its ability to eliminate Multiple Access Interferences (MAI) [19, 20].

Several techniques are used for SAC-OCDMA encoding and many codes are implemented [21-23], in our case we are mainly interested in FBGs (fiber Bragg gratings) being a promising candidate that offers various advantages [24-27]. FBGs are introduced as very narrow-band reflective filters which allow very specific wavelengths to be selected [28-31].

The optical SAC-OCDMA architecture is described in Sect. 2. Different simulations and discussion have been presented in Sect. 3. Finally, a conclusion is included in Sect. 4.

\section{System description}

The SAC-OCDMA system whose architecture is shown in Fig. 1 consists of three blocs : a transmitter, a transmission channel and a receiver. The transmitter is responsible for encoding the optical signal, the transmission channel is used to transmit the encoded signal and the receiver is meant to decode the transmitted coded signal.

Figure 1 shows that the transmitter is composed of three users operating in the same wavelength region $(1550.5 \mathrm{~nm})$. For each of them, the signal generated by a pseudo-random bit sequence generator is coded using a non-return to zero code. The generated sequence is modulated by a broadband optical source using Mach Zehnder modulator. Then, the modulated output signal is transmitted with a code signature.
Three fiber Bragg gratings are used to encode the optical signals and assign a signature code to each user. Note that the used FBGs have the same bandwidth with different Bragg wavelengths.

The modulated signals are combined using a $3 * 1$ optical combiner connected to the input of the optical fiber whose output is in turn linked to a $1 * 3$ optical splitter dividing the transmitted optical power into three parts corresponding to the three users. Then, a $1 * 2$ optical splitter is used to split the output optical signal corresponding to each user into two parts. The upper part is filtered out by a direct decoder which is the same encoder used at the transmitter, while the lower part is filtered out by its complementary decoder.

At the decoders output, two photodetectors are used in order to detect each optical signal component. Finally, an amplifier is used at the photodetectors output in order to amplify the resulting signals which will be then filtered out by a low pass filter.

Therefore, this SAC-OCDMA system architecture will be simulated using Optisystem network in order to realize the different results obtained in this paper.

\section{Simulation results and discussion}

In this section, we illustrate different simulation results related to an optical SAC-OCDMA system of 3 users and 9 users.

For a SAC-OCDMA system of 3 users, The simulations were performed in order to evaluate the transmission performance of the system by adjusting various factors, namely: Optical fiber length; FBG bandwidth; the bit rate and the optical power of the optical source used in the simulation.

Furthermore, for the SAC-OCDMA system of 9 users we will be interested in the evaluation of the effect of number of users on BER and $Q$ factor for different fiber lengths.

In our simulations, we use a white light source as a broadband optical source whose spectrum spread is between $1547.22 \mathrm{~nm}$ and $1553.79 \mathrm{~nm}$.

\subsection{Simulation of the performance of a SAC-OCDMA system of 3 users}

The different parameters'values used in this simulation are presented in Table 1.

Figure 2 shows the electrical signal data corresponding to the output of the Non-Return-to-Zero code for the three users.

The NRZ code is generally characterized by a continuous sign in each bit time. The electrical data is represented by a sequence of binary symbols where the pulse does 
Fig. 1 SAC-OCDMA system architecture for three users

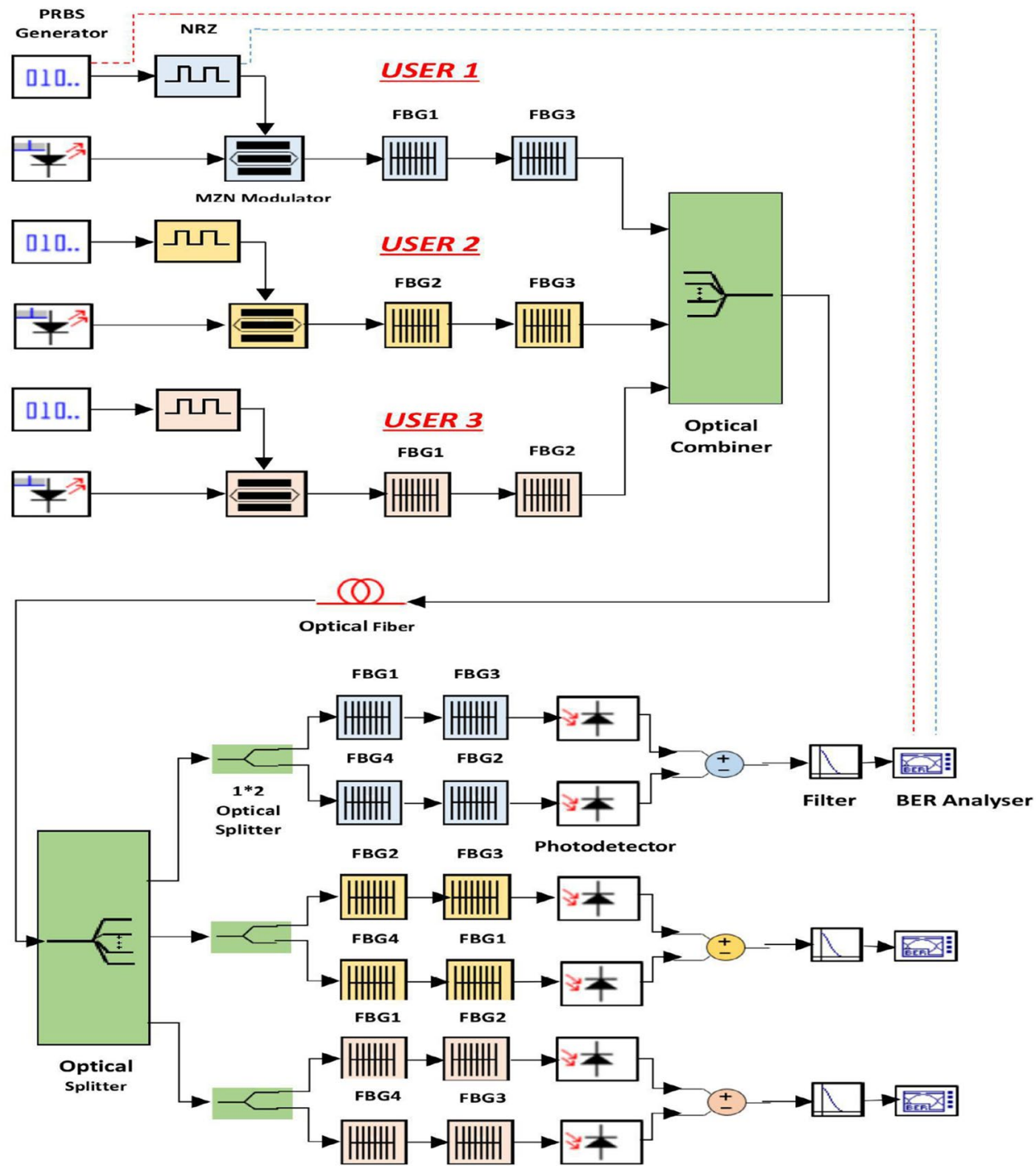

Table 1 Parameters values used in the simulation

\begin{tabular}{lll}
\hline Parameters & & Values \\
\hline White light source & $\begin{array}{l}\text { Operating wavelength region } \\
\text { Central wavelength }\end{array}$ & $\begin{array}{l}{[1547.22-1553.79] \mathrm{nm}} \\
1550.5 \mathrm{~nm}\end{array}$ \\
Signal format & & No-return to zero code (NRZ) \\
FBGs central wavelength & FBG1 & $1550.1 \mathrm{~nm}$ \\
& FBG2 & $1550.9 \mathrm{~nm}$ \\
& FBG3 & $1552.5 \mathrm{~nm}$ \\
Optical modulator extinction ratio & FBG4 & $1548.5 \mathrm{~nm}$ \\
Optical fiber & Reference wavelength & $30 \mathrm{~dB}$ \\
& Dispersion & $1550 \mathrm{~nm}$ \\
& Loss & $16.75 \mathrm{ps} / \mathrm{nm} / \mathrm{Km}$ \\
Receiver filter bandwidth & & $0.2 \mathrm{~dB} / \mathrm{Km}$ \\
\hline
\end{tabular}

not return to zero when two or more symbols follow each other.
Figure 3 shows the optical signals in the spectral domain at the output of the second FBG encoder assigning a signature code to each user and proves that the 
Fig. 2 The electrical signal data at the output of the NRZ code for a user 1, b user 2 and $\mathbf{c}$ user3

users' signature codes are different, which means that each user is characterized by its own signature code. This highlights the great importance of using FBGs as encoders that assign a unique code to each user, so that the distinction of the different signals at the output of the system is perfectly realized.

The two peaks shown in each figure correspond to the two Bragg wavelengths of the FBGs used for each user.

\subsubsection{Effect of optical power}

To evaluate the effect of the optical power of the broadband optical source on the bit error rate (BER), the simulation is performed for various values of the optical power with a bit rate of $200 \mathrm{Mbit} / \mathrm{s}$, a fiber length of $10 \mathrm{Km}$ and a FBGs bandwidth of $0.3 \mathrm{~nm}$.

Figures 4 and 5 list the variation of the quality factor $Q$ and the BER as a function of the optical power,respectively. For the user 1, we can note that a quality factor of 7.84 and a $B E R<10^{-9}$ are obtained when the optical power is around of $-100 \mathrm{dBm}$.

In addition, it can be noted that the BER corresponding to each user reaches an acceptable value when the optical power is set to $-110 \mathrm{dBm}$.

\subsubsection{Effect of FBG bandwidth}

The variation of the quality factor and the BER as a function of the FBG bandwidth for the three users are shown in Figs. 6 and 7, respectively. The simulation is performed for a fiber length of $10 \mathrm{Km}$ and a bit rate of $200 \mathrm{Mbit} / \mathrm{s}$.

The corresponding results indicate that the quality factor for user 1 reaches its maximum at a bandwidth value of $0.6 \mathrm{~nm}$, while for users 2 and 3 it reaches its maximum at a bandwidth value of $0.5 \mathrm{~nm}$. The BER at $0.6 \mathrm{~nm}$ FBG bandwidth is $1.50046 \times 10^{-24}, 3.33 \times 10^{-14}$ and $4.39006 \times 10^{-14}$ for user 1 , user 2 , and user 3 , respectively.

\subsubsection{Effect of the bit rate and fiber length}

In this section, the simulation is performed to estimate the studied system performance when the FBG bandwidth is $0.6 \mathrm{~nm}$.

Figures 8 and 9 show the variation of the BER as a function of the bit rate when a $10 \mathrm{Km}$ fiber length is used, and the variation of the BER versus the fiber length when the bit rate is $200 \mathrm{Mbit} / \mathrm{s}$, respectively.

Figure 8 proves that the simulated system remains performant for a bit rate of up to $350 \mathrm{Mbit} / \mathrm{s}$, From this value the BER is no longer acceptable.
을 Oscilloscope Visualizer

Dbl Click On Objects to open properties. Move Objects with Mouse Drag

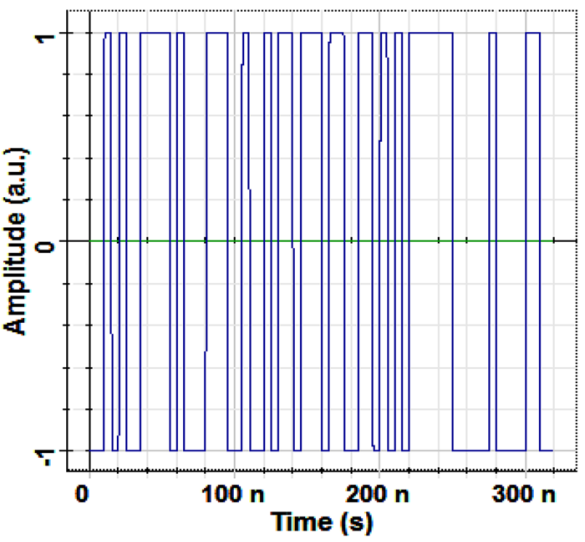

(a)

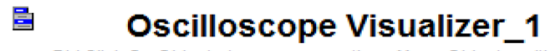
Dbl Click On Objects to open properties. Move Objects with Mouse Drag

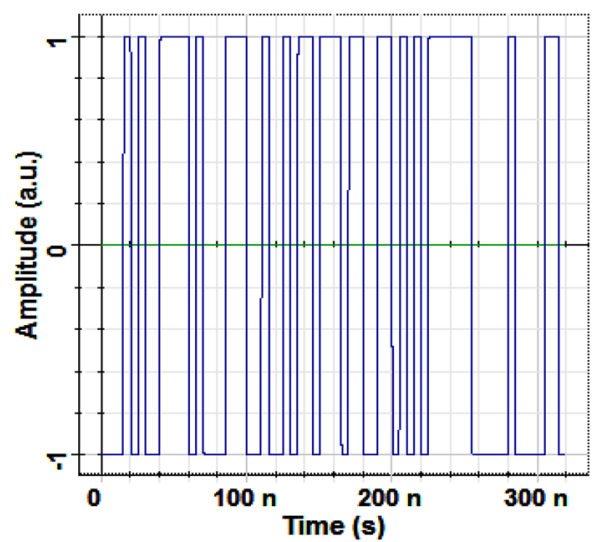

(b)

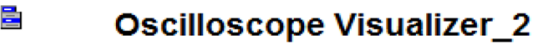

Dbl click On Objects to open properties. Move Objects with Mouse Drag

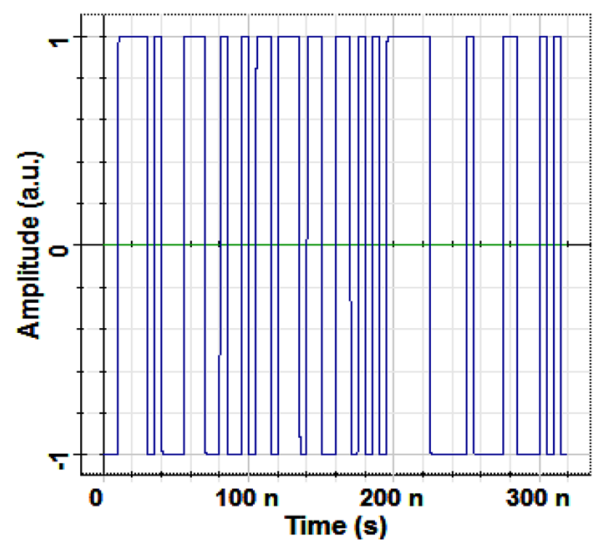

(c) 
Fig. 3 The optical signals at the output of the second FBG for a user 1, b user 2 and $\mathbf{c}$ user 3

Looking at Fig. 9, it is clear that the BER of each user is acceptable for fiber lengths less than $25 \mathrm{Km}$.

\subsection{Simulation of the performance of a SAC-OCDMA system of 9 users}

In order to increase the number of users and to simulate the performance of the proposed SAC-OCDMA system for a number of users greater than 3 , we used a second type of coding called m-sequence code, which is an orthogonal code allowing the generation of sequences of maximum length $N=2^{p}-1[32,33]$.

In our case, we worked with an m-sequence code of length equal to $15(p=4)$, so a number of users that is theoretically worth 15 users.

The fifteen wavelengths used in the encoding of our SAC-OCDMA system are taken in the spectrum range [1547.22 - 1553.79] $\mathrm{nm}$, and have the following values:

$\lambda_{1}=1547.3 \mathrm{~nm} \quad \lambda_{6}=1549.3 \mathrm{~nm} \quad \lambda_{11}=1551.3 \mathrm{~nm}$

$\lambda_{2}=1547.7 \mathrm{~nm} \quad \lambda_{7}=1549.7 \mathrm{~nm} \quad \lambda_{12}=1551.7 \mathrm{~nm}$

$\lambda_{3}=1548.1 \mathrm{~nm} \quad \lambda_{8}=1550.1 \mathrm{~nm} \quad \lambda_{13}=1552.1 \mathrm{~nm}$

$\lambda_{4}=1548.5 \mathrm{~nm} \quad \lambda_{9}=1550.5 \mathrm{~nm} \quad \lambda_{14}=1552.5 \mathrm{~nm}$

$\lambda_{5}=1548.9 \mathrm{~nm} \quad \lambda_{10}=1550.9 \mathrm{~nm} \quad \lambda_{15}=1552.9 \mathrm{~nm}$

The simulations performed in this part are carried out for a number of users that is equal to 9 users, with a FBGs' bandwidth of $0.3 \mathrm{~nm}$ and a bit rate of $100 \mathrm{Mbits} / \mathrm{s}$.

The optical signals in the spectral domain at the output of the seventh FBG encoder of users 2,5 and 9 are shown in Fig. 10. As mentioned in the section of the SACOCDMA system of 3 users, it can also be observed here that the optical signals of the different users are different, which means that each user has its unique code signature allowed by the seven FBGs used in the encoding process.

\subsubsection{Effect of number of users on $B E R$ for $L=15 \mathrm{Km}$, $\mathrm{L}=25 \mathrm{Km}$ and $\mathrm{L}=35 \mathrm{Km}$}

Figure 11 shows the variation of the BER as a function of the number of users for three different fiber lengths: $L=15$ $\mathrm{Km}, \mathrm{L}=25 \mathrm{Km}$ and $\mathrm{L}=35 \mathrm{Km}$.

During the simulations, we evaluated the BER achieved by each user when the total number of users increases. From the three graphs, we see that the BER of each user increases as the overall number of users increases.

Looking at Fig. $11 \mathrm{a}$ and $\mathrm{b}$ corresponding to $\mathrm{L}=15 \mathrm{Km}$ and $\mathrm{L}=25 \mathrm{Km}$, we can see that almost all users have a BER
를 Optical Spectrum Analyzer

Dbl Click On Objects to open properties. Move Objects with Mouse Drag

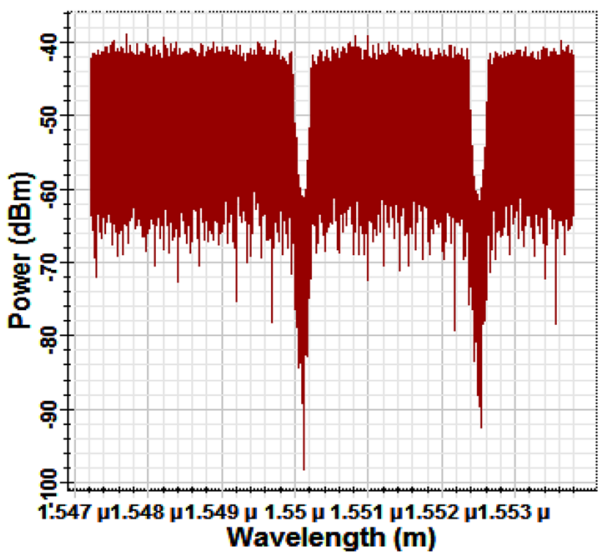

(a)

\section{莦 Optical Spectrum Analyzer_1}

Db Click On Objects to open properties. Move Objects with Mouse Drag

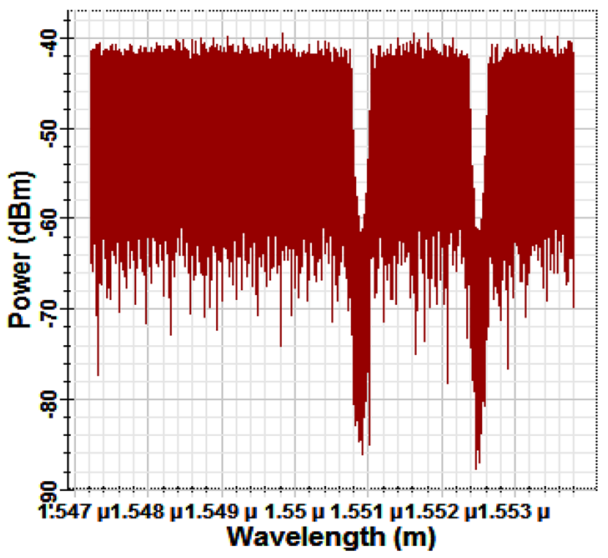

(b)

\section{是 Optical Spectrum Analyzer_2}

Dbl Click On Objects to open properties. Move Objects with Mouse Drag

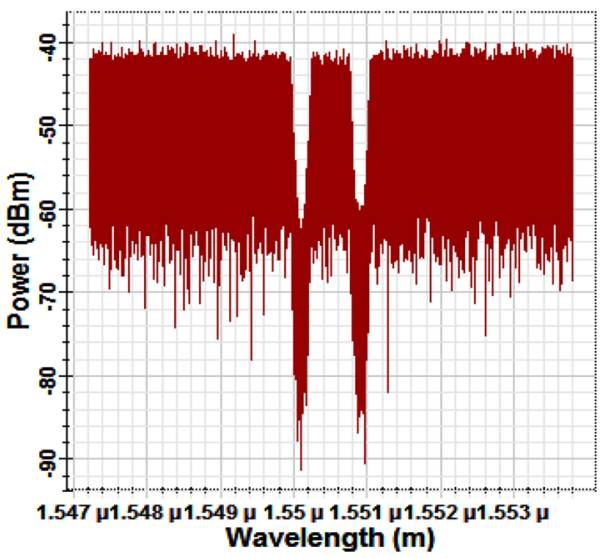

(c) 


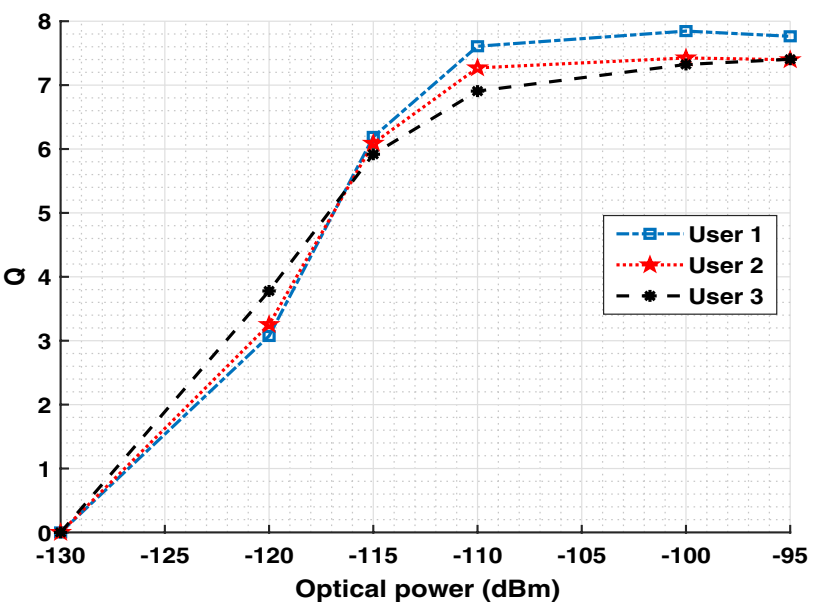

Fig. 4 Variation of Q factor versus the Optical power of the optical source

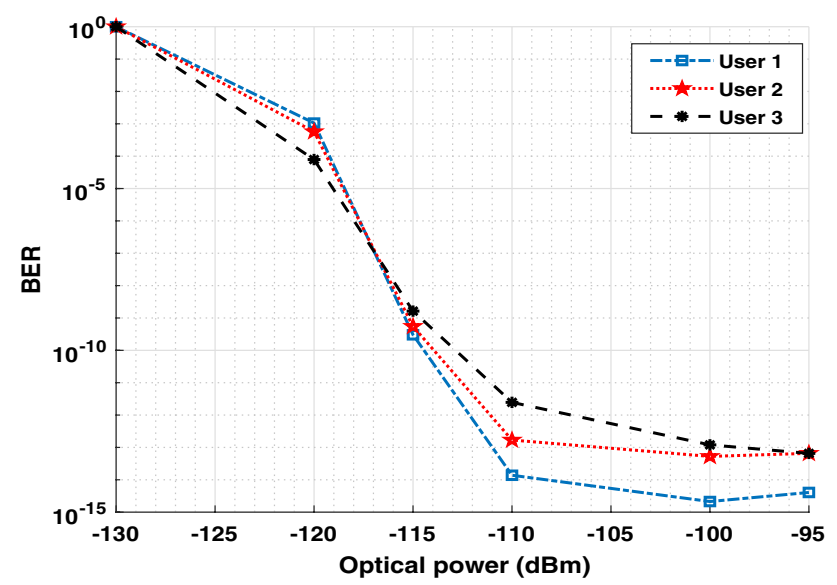

Fig. 5 Variation of BER versus the optical power of the optical source

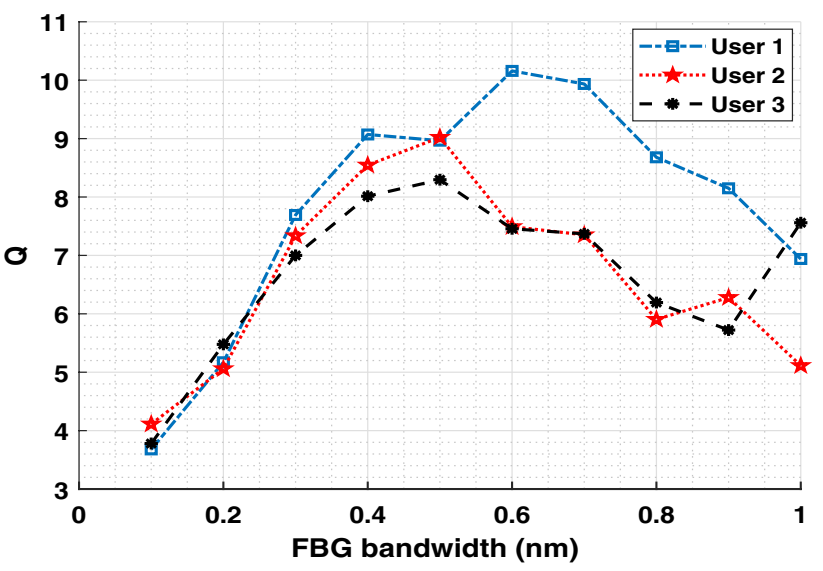

Fig. 6 Variation of Q factor versus FBG bandwidth for a $10 \mathrm{Km}$ fiber length

\section{SN Applied Sciences}

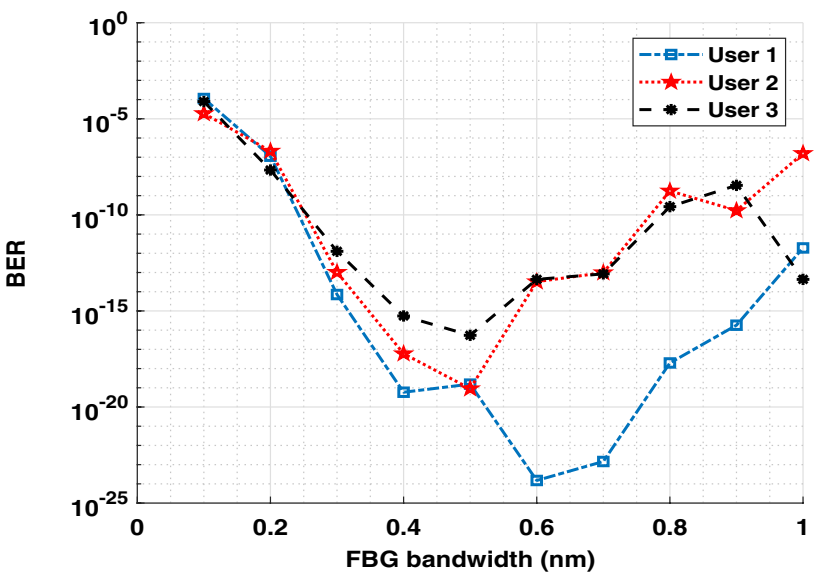

Fig. 7 Variation of BER versus FBG bandwidth for a $10 \mathrm{Km}$ fiber length

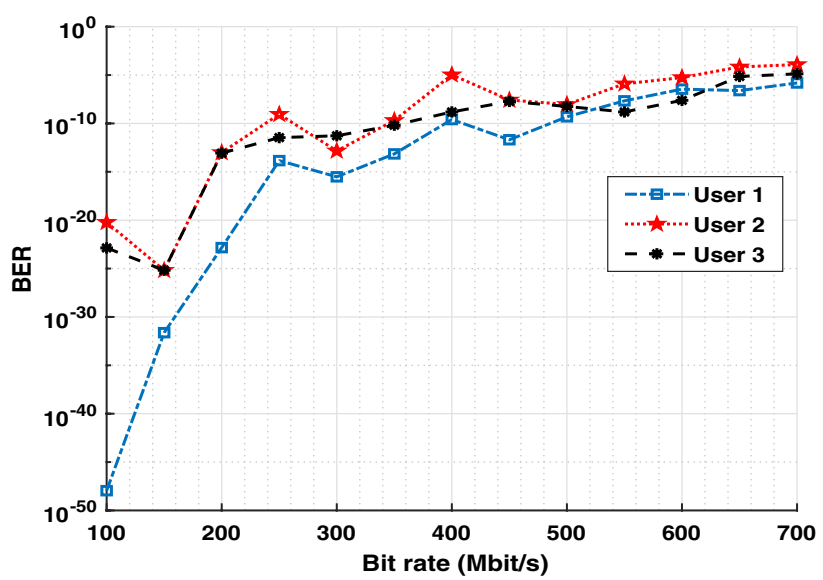

Fig. 8 BER as a function of bit rate

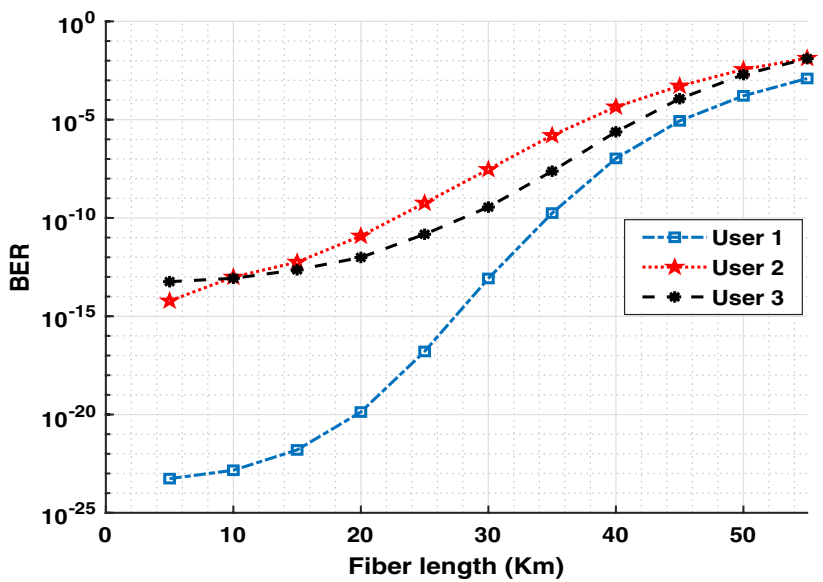

Fig. 9 BER as a function of fiber length 
Fig. 10 The optical signals at the output of the seventh FBG of a user 2 , b user 5 and c user 9

value close to the acceptable value $10^{-9}$, for a total number of users equal to 7 users.

For example, the BER corresponding to user 2 when the total number of users is 5 , is equal to $6.01761 \times 10^{-20}$ and $6.02501 \times 10^{-15}$ for $\mathrm{L}=15 \mathrm{Km}$ and $\mathrm{L}=25 \mathrm{Km}$, respectively whereas when the number of users is 7 , the BER is about $1.46769 \times 10^{-10}$ for $\mathrm{L}=15 \mathrm{Km}$ and $1.56094 \times 10^{-10}$ for $L=25 \mathrm{Km}$.

It should also be noted that for a SAC-OCDMA system of 8 or 9 users, there are a few users who reach an acceptable value of BER.

Similarly, with regard to the variation of the BER according to the number of users when $L=35 \mathrm{Km}$, we still see that the BER increases according to the number of users.

In this case, it can be noted that the total number of users where all users reach an acceptable BER value is reduced to 6 users. The BER is $5.45626 \times 10^{-14}, 1.35351 \times 10^{-10}, 6.96937 \times 10^{-12}, 2.01328 \times$ and $2.7205 \times 10^{-13}$ for users $2,3,4,5$ and 6 , respectively.

\subsubsection{Effect of number of users on $Q$ factor for different fiber lengths}

The variation of the quality factor $Q$ as a function of the number of users for different fiber lengths is shown in Fig. 12.

This Figure depicts that the quality factor $Q$ of all users decreases as the number of users increases.

For $\mathrm{L}=5 \mathrm{Km}$, the quality factor remains good for a number of users up to 8 users and is equal to 5.8810 on average. For $L=15 \mathrm{Km}$ and $L=25 \mathrm{Km}$, the quality factor $Q$ is generally acceptable for 7 users in total. Finally, for $L=35$ $\mathrm{Km}$, the total number of users for which the quality factor provides a good value is 6 users and is worth 6.3845 .

\section{Conclusion}

Several simulations had been processed in order to evaluate the SAC-OCDMA system performance. The results carried out have shown that the system performance is influenced and pending on the variation of several intrinsic factors such as: The FBG's bandwidth; the bit rate, the fiber length and the number of users.

The obtained results indicate that the transmission quality of a SAC-OCDMA system of 3 users remains good for a fiber length of up to $25 \mathrm{Km}$ and a FBG bandwidth of $0.6 \mathrm{~nm}$.
Optical Spectrum Analyzer_3

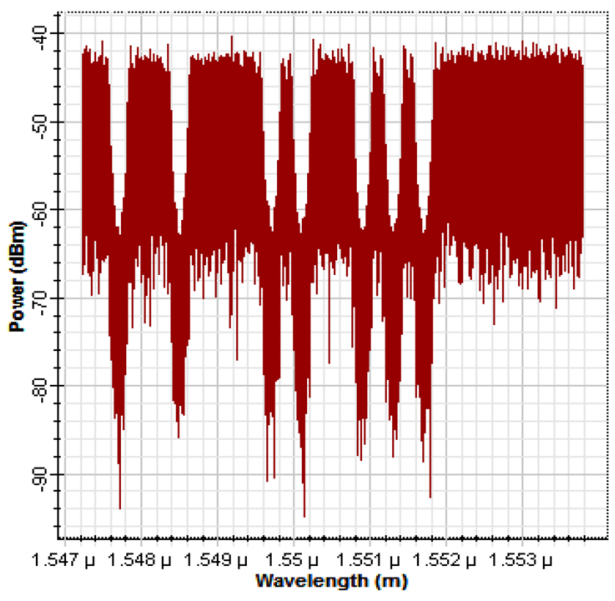

(a)

룜 Optical Spectrum Analyzer_17

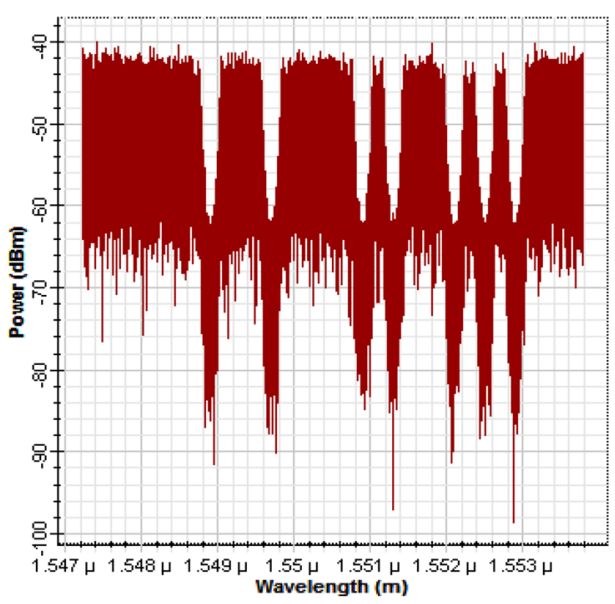

(b)

붑 Optical Spectrum Analyzer_26

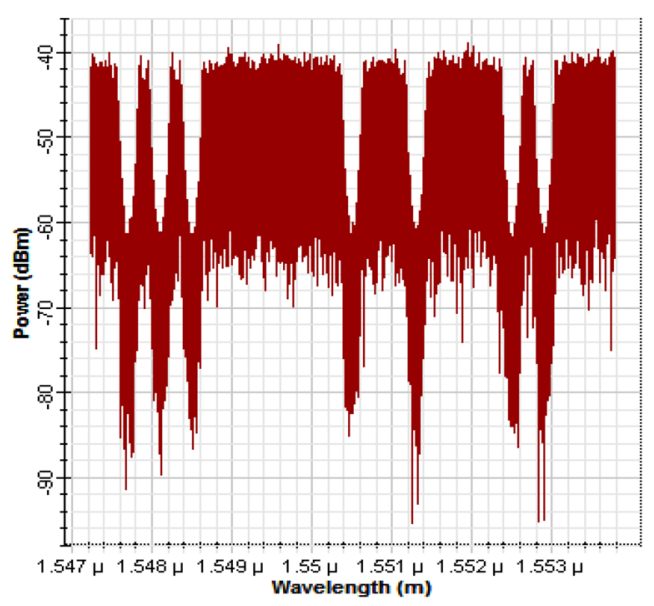

(c) 


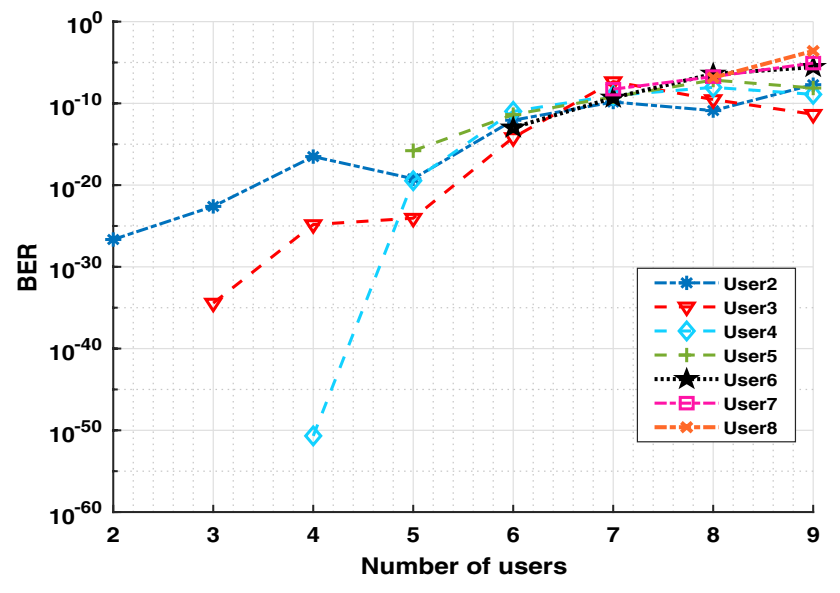

(a)

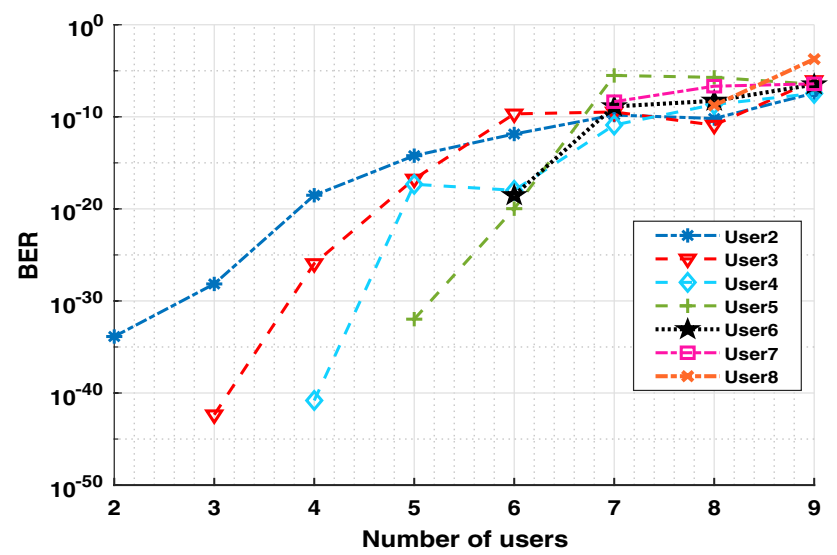

(b)

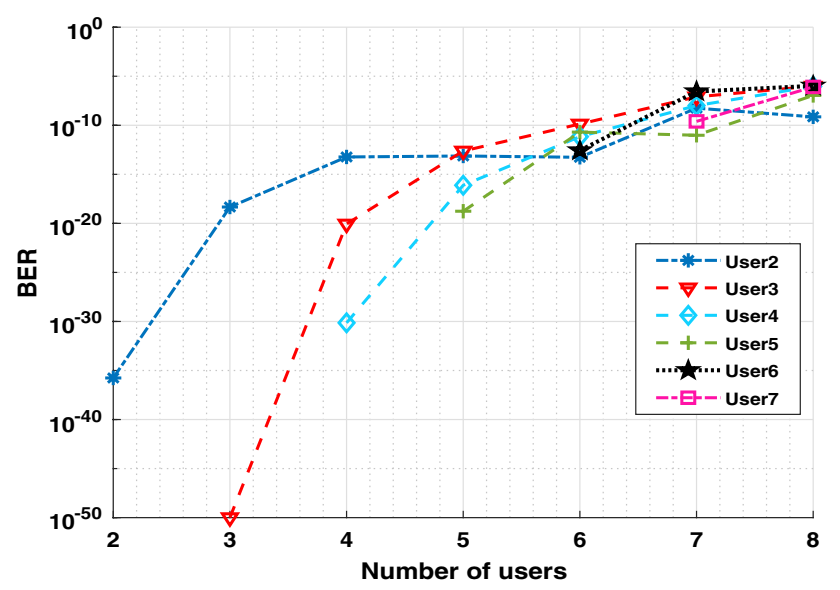

(c)

Fig. 11 BER versus number of users for $\mathbf{a} L=15 \mathrm{Km}, \mathbf{b} L=25 \mathrm{Km}$ and $\mathrm{CL}=35 \mathrm{Km}$

Based on the same SAC-OCDMA system architecture used for 3 users, the number of users was increased to 9 users. The simulation performed showed that the

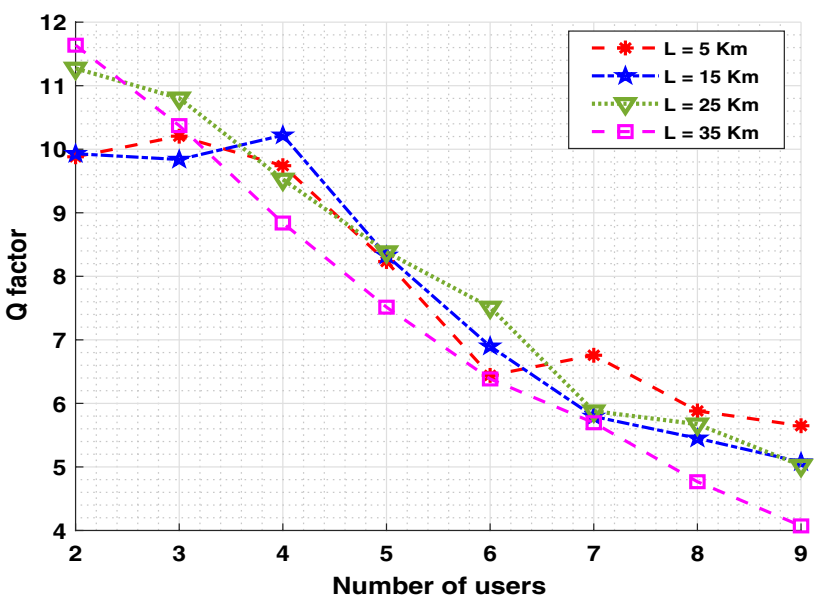

Fig. $12 \mathrm{Q}$ factor versus number of users for different fiber lengths

proposed system remains performant for a number of users of up to 8 users with a fiber length of $5 \mathrm{Km}$. As well, a fiber length of up to $35 \mathrm{~km}$ can be used for a SAC-OCDMA system of 6 users. And as the fiber length increases, the number of possible users decreases.

Finally, we can point out that SAC-OCDMA systems have great importance and multiple applications in our daily life; they are very effective in different fields. It allows users of telecommunication services to benefit from higher data rates and faster service, and also offers great security thanks to the use of very narrow-band filters.

\section{Compliance with ethical standards}

Conflicts of interest The authors declare that they have no conflict of interest.

\section{References}

1. Zhang X, Hraimel B, Wu K (2011) Breakthroughs in optical wireless broadband access networks. IEEE Photon J 3(2):331

2. Berthold J, Saleh AA, Blair L, Simmons JM (2008) Optical networking: past, present, and future. J Lightwave Technol 26(9):1104

3. Maslouhi I, Ghoumid K, Baibai K (2018) Analysis of end-to-end packet delay for internet of things in wireless communications. Int J Adv Comput Sci Appl 9(9):338

4. Cvijetic N (2014) In: 2014 16th international telecommunications network strategy and planning symposium (networks). IEEE, pp $1-5$

5. Ghoumid K, Mekaoui S, Ouariach A, Cheikh R, Nougaoui A, Gharbi T (2015) Tunable filter based on cavity electro-optic modulation for dwdm applications. Opt Commun 334:332

6. Kaur N, Goyal R, Rani M (2017) A review on spectral amplitude coding optical code division multiple access. J Opt Commun 38(1):77

\section{SN Applied Sciences}


7. Castro JM, Geraghty DF (2006) In: Optical fiber communication conference, optical society of America, p OWI62

8. Penon J, El-Sahn ZA, Rusch LA, LaRochelle S (2007) Spectralamplitude-coded ocdma optimized for a realistic fbg frequency response. J Lightwave Technol 25(5):1256

9. Ab-Rahman MS, Shaarani M (2008) The proposal of ocdma encoder based on optical cross and add-and-drop multiplexer (oxadm)-device characteristic. Int J Comput Sci Netw Secur 8:259

10. Al-Khafaji H, Aljunid S, Fadhil H (2012) Spectral efficiency analysis of bipolar spectral-amplitude coding optical code-division multiple-access systems using different one-dimensional codes. IET Optoelectron 6(5):215

11. Sahbudin R, Abdullah M, Mokhtar M (2009) Performance improvement of hybrid subcarrier multiplexing optical spectrum code division multiplexing system using spectral direct decoding detection technique. Opt Fiber Technol 15(3):266

12. Abd TH, Aljunid S, Fadhil HA (2013) A new code design for spectral amplitude coding optical cdma systems using fiber bragggrating. J Opt 42(2):110

13. Bharti M, Kumar M, Sharma AK (2018) A novel technique to detect code for sac-ocdma system. J Opt Commun 39(2):215

14. Saad NM (2005) Contribution à l'étude de l'application de la technique cdma aux systèmes de transmission optique. Ph.D. thesis, Limoges

15. Driz $S$ et al (2018) Contribution à l'étude du système hybride $\mathrm{scm}$ sac-ocdma. Ph.D. thesis

16. Laribi HFZ, Aissa Madaoui S (2016) Etude d'un système ocdma avec les codes hadamard pour les signaux optiques incohérents. Ph.D. thesis

17. El-Mottaleb S Abd, Fayed H, El-Aziz AA, Metawee M, Aly M (2018) Enhanced spectral amplitude coding ocdma system utilizing a single photodiode detection. Appl Sci 8(10):1861

18. Farhat A, Menif M, Rezig H (2011) In: 2011 13th international conference on transparent optical networks. IEEE, pp 1-4

19. El Mottaleb SAA, Fayed HA, El Aziz AA, Aly MH (2014) Sac-ocdma system using different detection techniques. J Electron Commun Eng ep-ISS1:2278-8735

20. Huang JF, Tsai CM, Lo YL (2004) Compensating fiber gratings for source flatness to reduce multiple-access interferences in optical cdma network coder/decoders. J Lightwave Technol 22(3):739

21. Alayedi M, Cherifi A, Hamida AF (2019) In: 2019 6th international conference on image and signal processing and their applications (ISPA). IEEE, pp 1-4

22. Bouarfa A, Kandouci M (2016) Performance of spectral amplitude coding ocdma using multi-identity high power code. J Adv Comput Netw 4(4):184
23. El-Mottaleb SAA, Fayed HA, Aly MH, Rizk MR, Ismail NE (2019) An efficient sac-ocdma system using three different codes with two different detection techniques for maximum allowable users. Opt Quantum Electron 51(11):354

24. Ghoumid K, Ferriere R, Benkelfat BE, Guizal B, Gharbi T (2010) Optical performance of bragg gratings fabricated in ti:linbo3 waveguides by focused ion beam milling. J Lightwave Technol 28(23):3488

25. Ferriere R, Benkelfat BE, Dudley JM, Ghoumid K (2006) Bragg mirror inscription on linbo3 waveguides by index microstructuration. Appl Opt 45(15):3553

26. Teh PC, Petropoulos P, Ibsen M, Richardson DJ (2001) A comparative study of the performance of seven-and 63-chip optical code-division multiple-access encoders and decoders based on superstructured fiber Bragg gratings. J Lightwave Technol 19(9):1352

27. Wei Z, Ghafouri-Shiraz H, Shalaby H (2001) New code families for fiber-bragg-grating-based spectral-amplitude-coding optical cdma systems. IEEE Photon Technol Lett 13(8):890

28. Ghoumid K, Ghadban A, Boukricha S, Yahiaoui R, Mekaoui S, Raschetti M, Lepers C et al (2019) Spectral coded phase bipolar ocdma technological implementation thanks to low index modulation filters. Telecommun Syst 73:433-441

29. Ghoumid K, Elhechmi I, Mekaoui S, Gharbi T (2013) Multi-wavelength filtering wideband by cascade bragg reflectors in optical waveguides. Int J Inf Electron Eng 3(5):506

30. Ghoumid K, Elhechmi I, Mekaoui S, Pieralli C, Gharbi T (2013) Analysis of optical filtering in waveguides with a high index modulation using the extended coupled mode theory by hybridization of a matrix method. Opt Commun 289:85

31. Ghoumid K, Benkelfat BE, Ferriere R, Ulliac G, Gharbi T (2011) Wavelength-selective ti:linbo3 multiple y-branch coupler based on focused ion beam milled bragg reflectors. J Lightwave Technol 29(23):3536

32. Fsaifes I (2007) Encodage et décodage temporels" tout-optique" à réseaux de bragg pour l'accès multiple. Ph.D. thesis

33. Hanane D (2018) Evaluation des performances de la technique cdma dans la transmission optique. Ph.D. thesis, Université de Batna

Publisher's Note Springer Nature remains neutral with regard to jurisdictional claims in published maps and institutional affiliations. 